Salford, and I reported to the Society of British Neurological Surgeons a number of such enterogenous cysts, the most interesting of the series being a young boy who had been operated on as an infant for a mesenteric cyst which had produced melaena. At the age of 10 years he came under the care of Dr. C. E. C. Wells with an intraspinal cyst in the cervicothoracic region, the presence of which was confirmed by myelography. In the absence of any progressive neurological signs laminectomy was not considered necessary or desirable. There was a circular defect in the body of Dl or D2 which contained the "stalk" of an intrathoracic cyst $5 \mathrm{~cm}$ in diameter, which was subsequently removed by $\mathrm{Mr}$. T. $\mathrm{H}$. Rosser at Sully Hospital. The combination of all these lesions in one patient throws additional light on the embryology and pathology of these remarkable lesions.-I am, etc.,

Protestant Hospital,

Republic of the Ivory Coast

Charles Langmaid

\section{Further Application of the Nitroblue Tetrazolium Test}

SIR,-The claim by Dr. R. M. Rowan and others that the N.B.T. test can be helpful in distinguishing between thromboembolism and lobar pneumonia (3 August, p. 317) is both interesting and surprising. They refer to our prospective study ${ }^{1}$ but do not emphasize our view that, in general, the N.B.T. test, whether performed by the original method or by the same modified method as they have used, ${ }^{2}$ was of no value in distinguishing pyogenic bacterial infection from other disorders even when performed by highly experienced observers. Though they were correct in stating that this "experience contrasts with that of most previous workers," three subsequent well controlled studies have supported our observations that the N.B.T. test is of minimal value in the differential diagnosis of pyogenic infection..$^{3-5}$

It is now known that the N.B.T. test measures the phagocytosis of particulate complexes of N.B.T. and heparin and fibrinogen by neutrophils, or both. ${ }^{7}$ The phagocytosis of these complexes may be stimulated in ill patients as part of the acute phase reaction, possibly by the acute phase protein orosomucoid. ${ }^{9}$ Immature neutrophils are unable to respond to these stimuli.

Raised N.B.T. test results in patients after myocardial infarction 1011 and operation clearly indicate that false-positive results may occur in acutely ill patients in the absence of sepsis. It is surprising, therefore, that universally low N.B.T. scores were obtained in patients with uncomplicated pulmonary thromboembolism by Dr. Rowan and colleagues. They appear to be comparing a group of patients, most of whom were postoperative or post-partum with pulmonary thromboembolism, with a group with lobar pneumonia who had not undergone operation. This trial was uncontrolled in that other postoperative patients or patients ill from other conditions were not studied. For a valid trial it is essential that both groups be uniform in all but the specific conditions being evaluated. N.B.T. test results may be raised postoperatively and become negative at a time when serum concentration of acute phase proteins are still raised.12 This sug- gests that there may be a defect in the ability of neutrophils to phagocytose complexed N.B.T. despite the stimulus of orosomucoid, possibly because of the replacement of circulating mature neutrophils by less mature ones as a result of the enhanced turnover of these olls associated with inflammation induced by operation. ${ }^{13}$

The initial enthusiasm for the value of the N.B.T. test as a non-specific indicator of bacterial infection has not withstood subsequent critical evaluation. This experience provokes us to advise caution before accepting its value in the particular role advocated by Dr. Rowan and colleagues. Their study is unique and thus not subject to direct comparicon, but we feel that their results require confirmation using adequate controls and patients with a wider spectrum of symptomatology and disease severity before any diagnostic or therapeutic decisions are reached as a direct result of N.B.T. tests Until then we would support the view that "N.B.T. reduction is an interesting tinctorial reaction, but it seems most unwise in individual cases to rely on it for importan decisions regarding the application of antimicrobial therapy."14-We are, etc.,

A. W. SEgAI

A. J. LEVI

Northwick Park Hospital and Clinical Research Centre,

1 Segal, A. W., Trustey, S. F., and Levi, A. J., Lancet, 1973, 2, 879.
2 Gordon, A. M., et al., fournal of Clinical
Pathology, 1973, 26, 52.

Steigbigel, R. T., Johnson, P. K., and Remington, J., New 235 .

Bittner, S. J., et al., American foumal of Clinical Pathology, 1973, 60, 843.

conattrakul, W., and Andersen, B. R., Archives of Internal Medicine, 1973, 132, 529 .

Segal, A.W., and Levi, A. J., Clinical Science Medicine, 1973, 45, 817.

egal, A. W., M.D. Thesis, University of Cape

174.' G., and Schmitz, A., Lancet, 1974, 2, Segal, A. W., and Levi, A. J., Clinical Science and Molecular Medicine. In press.

Lauter, C. B., et al., Annals of Internal Medicine, $1973,79,59$.

Shafar, J., Behr, G., and Rusius, J., foumal of Clinical Pathology, 1974, 27, 399

Aronsen, K. F. et al., Scandinavian foumal of Suppl. No. 124, p. 127 .

13 Boggs, D. R., New England foumal of Medicine, Nathan, D. G., New England Fournal of
Medicine, 1974, 290, 280.

\section{Psychiatry in the Soviet Union}

SIR,-Professor J. K. Wing (10 August, p 408 ) is encouraged by someone's statement that Dr. Zhores A. Medvedev's compulsory admission to a mental hospital was "an error." It would be more encouraging if Professor Wing could furnish us with some details-for example, who admitted the error? Was it Professor A. V. Snezhnevsky (Chief Psychiatrist of the U.S.S.R.), Professor George Morozov (Director of the Serbsky Institute), or Dr. A. Y. Lifshits (Head of the Kaluga Psychiatric Hospital)?

Was any promise made to hold an inquiry? Professor Wing is rather vague here. He hints that an inquiry may have been held but that he "may" have missed a public announcement about it. The error is said to have been frankly acknowledged at the Serbsky Institute on 15 October 1973, 10 months ago. It is discouraging that Professor Wing still cannot enlighten us as to what vent wrong to cause the incarceration of an eminently sane scientist.-I am, etc.,

Weybridge, Surrey

I. ATKIN

\section{Organic Psychosis}

SIR,-It was interesting to see your leading article (27 July, p. 214) on organic psychosis I wish to report a case of organic psychosis due to a once common but now rare cause -namely, bromide poisoning.

A 57-year-old woman was admitted to hospital after several days' disturbed behaviour. She had a recent history of neurotic depression and possibly barbiturate abuse. She was unkempt and fearful but had no focal signs other than sluggish pupillary light reflexes, dysarthria, ataxia, and tremor. Mentally she showed clouding of consciousness, disorientation, memory defects, of consciousness, disorientation, memory defects, and perseveration. A provisional diagnosis of a toxic confusional state was made and the condition
ascribed to barbiturate abuse until the serum barascribed to barbiturate abuse until the serum bar-
biturate level was found to be zero. Investigations revealed no evidence of metabolic, endocrine, or cerebrovascular disorder, and no evidence of infection or trauma was found. The E.E.G. was abnormal, with diffuse runs of slow and fast waves and short periods of inactivity. The C.S.F. was normal except for a pressure of $180 \mathrm{~mm}$. Her clinical state cerum bromide not improved after a week, and a cerum brame as a "long shot," was $250 \mathrm{mg} / 100 \mathrm{ml}$. Salt and a thiazide diuretic were given and the patient's mental state improved slowly over the following four weeks. In a home search bottles of a proprietary nerve tonic which contained nearly $30 \% \mathrm{w} / \mathrm{v}$ bromide salts were found.

Recently there has been renewed interest in bromide poisoning. Carney's review ${ }^{1}$ suggests that bromism should still be excluded as an aetiological agent in organic psychoses. My own experience of two cases in six months would tend to confirm this. I believe some doctors continue to prescribe bromides as hypnotics, and there are a number of proprietary bromide preparations available without prescription as nerve tonics and cough mixtures. On removal from the source of bromide some cases of bromism initially worsen. ${ }^{12}$ Most cases recover slowly as the ion is excreted. Hence the condition may remain undiagnosed even in hospital and the patient might return to bromide abuse on discharge. Increased awareness of bromism may lead to detection of more cases and prevention of others. - I am, etc.,

Whitchurch Hospital,

RICHARD J. W. WILLIAMS

1 Carney, M. W. P., Lancet, 1971, 2, 523. Levin, M., American fourmal of Psychiatry, 1948,
104, 798.

\section{Swelling of Arm in Patients With} Arteriovenous Fistula

SIR,-In haemodialysis patients with a Cimino-Brescia arteriovenous fistula swelling of the fistula arm with oedema and phlebectasis has been observed. The cause of the swelling is not always clear. Recently we saw a patient with this condition.

A 75-year-old man with prostatic carcinoma had a side-to-side fistula between the radial artery and the cephalic vein made in his left arm for intravenous injections of a cytostatic drug. ${ }^{1}$ The fistula functioned well and caused the patient no inconvenience. After an episode of precordial pains a blood sample was drawn from a subcutancous vein close to the fistula. As bleeding occurred from the puncture site a fairly tight compression bandage was puncture site a fairly tight compression bandage was hours later the patient had pain and swelling of the arm and hand distal to the bandage. After five hours 